\title{
Modelling solute transport in soil columns using advective-dispersive equations with fractional spatial derivatives
}

\author{
F. San Jose Martinez , Y.A. Pachepsky , W.J. Rawls \\ Technical University of Madrid (UPM), Madrid, Spain \\ USDA-ARS, Beltsville, MD, USA
}

Keywords:

Fractional derivatives

Fractional advective-dispersive equation

Solute transport

Porous media

Soil columns experiments

\begin{abstract}
A B S T R A C T
Solute transport in soils is commonly simulated with the advective-dispersive equation, or $\mathrm{ADE}$. It has been reported that this model cannot take into account several important features of solute movement through soil. Recently, a new model has been suggested that results in a solute transport equation with fractional spatial derivatives, or FADE. We have assembled a database on published solute transport experiments in soil columns to test the new model. The FADE appears to be a useful generalization of the ADE. The order of the fractional differentiation reflects differences in physical conditions of the solute transport in soil.
\end{abstract}

\section{Introduction}

Advection and hydrodynamic dispersion are considered to be the dominant mechanisms of solute transport in the vadose zone, i.e. the variably saturated layer of soils and sediments between the soil surface and the aquifers [1]. The advection is associated with the average water flux or velocity. The hydrodynamic dispersion is conceptualised as a diffusion-like process and can be interpreted as the result of the Brownian motion of solute particles [2]. Under these assumptions, the parabolic advective-dispersive equation $(A D E)$

$\frac{\partial c}{\partial t}=D \frac{\partial^{2} c}{\partial x^{2}}-v \frac{\partial c}{\partial x}$

is the mass conservation equation for the transport of inert (conservative) solute in homogeneous rigid porous media with stationary water flow. In Eq. (1), $c$ is the solute concentration $\left[\mathrm{M} \mathrm{L}^{-3}\right], D$ is the dispersion coefficient $\left[\mathrm{L}^{2} \mathrm{~T}^{-1}\right], v$ is the average pore water velocity $\left[\mathrm{LT}^{-1}\right], x$ is the distance [l], and $t$ is the time [T]. The ADE has served as the theoretical framework to model the fate and transport of chemicals, and to address critical environmental issues stemming from agricultural practices or waste disposal operations in last decades [1].

The ADE fails to capture some important features of solute transport in soils [3-8]. On the one hand, the dispersion coefficient tends to increase with the distance of solute concentration observations. This is often mentioned as the scale effect on the dispersion process [9]. On the other hand, solute concentrations at the outlet of the soil columns approach expected asymptotic values slower than predicted by the ADE; the phenomenon is known as heavy tailing [10-12]. Such behaviour is sometime referred to as the anomalous or the non-Fickian dispersion.

The basic assumption of the ADE models for the transport of contaminants through soil is that the movements of solute particles are characterized by the Brownian motion [2]. The complexity of pore space in natural porous media makes the hypothesis of the Brownian motion far too restrictive in some cases. It has been suggested that, in the soil matrix, high velocity regions tend to be spatially continuous at all scales, and therefore a solute particle travelling faster than the mean is likely to do that over large distances. Similarly, slower particles are trapped in stagnant zones before they have a chance to move in the general direction of the flow. Invoking the notion of the Lévy motion can simulate this type of solute particle transport. The lévy motion is a broader framework compared with the Brownian motion, and includes the persistence in movements of solute particles. Significant deviations from the mean are more likely to occur in Lêvy motions than in the Brownian movement $[13,14]$. These features make lévy motion an attractive generalization of Brownian motion when describing solute transport in porous media $[9,15]$. Brownian motion is a specific case of the Lévy motion.

Similarly to the ADE that can be derived assuming Brownian motion [2], solute transport equations can be derived for Lévy motions [16-22]. These equations include fractional derivatives. The 
one-dimensional version of the fractional advective-dispersive equation (FADE) with symmetric dispersion is

$\frac{\partial c}{\partial t}=-v \frac{\partial c}{\partial x}+\frac{1}{2} D_{f}\left(\frac{\partial^{\alpha} c}{\partial_{+} x^{\alpha}}+\frac{\partial^{\alpha} c}{\partial_{-} x^{\alpha}}\right)$

Here, $D_{f}$ is the fractional dispersion coefficient $\left[\mathrm{L}^{\alpha} \mathrm{T}^{-1}\right]$, the superscript $\alpha$ is the order of fractional differentiation, $1<\alpha \leqslant 2, c$ is the solute concentration $\left[\mathrm{M} \mathrm{L}^{-3}\right], v$ is the flow velocity $\left[\mathrm{L} \mathrm{T}^{-1}\right], x$ is the distance $[\mathrm{L}]$, and $t$ is the time $[\mathrm{T}]$. Fractional derivatives are integro-differential operators defined as [23]:

$\frac{\partial^{\alpha} c}{\partial_{+} x^{\alpha}}(x, t)=\frac{1}{\Gamma(m-\alpha)} \frac{\partial^{m}}{\partial x^{n t}} \int_{A}^{x}(x-z)^{m-\alpha-1} c(z, t) d z$

for the left-sided fractional derivative, and

$\frac{\partial^{\alpha} c}{\partial_{-} x^{\alpha}}(x, t)=\frac{(-1)^{m}}{\Gamma(m-\alpha)} \frac{\partial^{m}}{\partial x^{n t}} \int_{x}^{B}(z-x)^{m-\alpha-1} c(z, t) d z$

for the right-sided fractional derivative. Here, $m$ is the integer such that $m-1<\alpha \leqslant m, \Gamma$ is the gamma function and $A$ and $B$ are real numbers. Let us remark that in the case $\alpha=2$ the FADE reduces to the ADE.

The FADE as a model to simulate solute transport in soils has been applied to data from both laboratory and filed-scale experiments $[20,18,9,24-29]$. Laboratory data are obtained from the so called miscible displacement experiments, in which the tracer solution infiltrates into originally tracer-free soil columns, and the dependence of the tracer concentration at the outlet on time, or breakthrough curve (BTC), is measured during the infiltration.

Most of the applications of the FADE to the solute transport todate rely on analytical solutions of the initial value problem in the infinite domain. However, in many practical applications initialboundary value problems in a finite domain need to be considered and numerical solutions are required. Several methods had been developed to solve the FADE numerically in the past few years $[30-32,27,33,34,28,29]$.

The objective of this work was to compare the performances of both the classical model (ADE) and the fractional one (FADE) using a mass-conserving boundary condition and the numerical solution. We used published breakthrough data from miscible displacement experiments.

\section{Numerical solution of FADE for soil columns}

To derive a numerical scheme to solve FADE for finite length soil columns, we make use of Grünwald definitions of the left- and the right-sided fractional derivatives ( 3 ) and ( 4 ); for $1<\alpha \leqslant 2$ they are, respectively,

$\frac{\partial^{\alpha} c}{\partial_{+} x^{\alpha}}(x, t)=\lim _{M_{+}-\infty} \frac{1}{h_{+}^{\alpha}} \sum_{k=0}^{M_{+}} g_{k} c(x-k h, t)$

and

$\frac{\partial^{\alpha} c}{\partial x^{\alpha}}(x, t)=\lim _{M_{-} \rightarrow \infty} \frac{1}{h_{-}^{\alpha}} \sum_{k=0}^{M_{-}} g_{k} c(x+k h, t)$

where $M_{t}$ are positive integers, $h_{+}=x / M_{+}, h_{-}=(L-x) / M_{-}, L$ is the length of the column. We have chosen $A=0$ and $B=L$ in Eqs. (3) and (4), respectively. The Grünwald weights $g_{k}$ are defined as

$g_{0}=1, \quad g_{k}=(-1)^{k} \frac{\alpha(\alpha-1) \cdots(\alpha-k+1)}{k !}$

In order to setup a numerical scheme let $M$ be a nonnegative integer, $h$ a real number such that $h=L / M$ and $x=i h$, $i=0,1, \ldots, M$, for $0 \leqslant x_{i} \leqslant L$; also $t_{n}=n \Delta t$, so that $c_{i}^{n}=c\left(x_{i}, t_{n}\right)$. For the purpose of obtaining a stable numerical scheme, we used the shifted Gı̈̈inwald approximation to the left-sided fractional derivatives (5) $[33,34]$

$\frac{\partial^{\alpha} c}{\partial_{+} x^{\alpha}}\left(x_{i}, t_{n}\right) \approx \frac{1}{h^{\alpha}} \sum_{k=0}^{M} g_{k} c\left(x_{i}-(k-1) h, t_{n}\right)$

and the shifted Grünwald approximation to right-sided fractiona] derivatives (6)

$\frac{\partial^{\alpha} c}{\partial \_x^{\alpha}}\left(x_{i}, t_{n}\right) \approx \frac{1}{h^{\alpha}} \sum_{k=0}^{M} g_{k} c\left(x_{i}+(k-1) h, t_{n}\right)$

In these expressions $g_{k}$ stand for the Grünwald weights (7). These approximations can be used in an explicit finite difference scheme for FADE

$\frac{c_{i}^{n+1}-c_{i}^{n}}{\Delta t}=-v \frac{c_{i}^{n}-c_{i-1}^{\prime \prime}}{h}+\frac{D_{s f}}{2 h^{\alpha}}\left\{\sum_{k=0}^{M} g_{k} c_{i-k+1}^{n}+\sum_{k=0}^{M} g_{k} c_{i+k-1}^{n}\right\}$

Note that for $\alpha=2$, expressions ( 8 ) and (9) reduce to the standard centred difference formula for the second derivative and the explicit finite difference scheme (10) reduces to the standard explicit finite difference scheme for ADE. In the internal points of the spatial domain, $(i=1, \ldots, M-1)$, one has

$c_{i}^{n+1}=B \sum_{k=0}^{i+1} g_{k} c_{i-k+1}^{n}+E c_{i-1}^{n}+(1-E) c_{i}^{n}+B \sum_{k=0}^{M-i+1} g_{k} c_{i+k-1}^{n}+\Delta t s_{i}^{n}$

Here $B=D \Delta t / 2 h^{\alpha}$ and $E=v \Delta t / h$. The stability condition is $v \Delta t /$ $h+\alpha D \Delta t / h^{*} \leqslant 1$.

Boundary conditions are needed to obtain the system of linear equations to find $c_{i}^{n+1}$, from $c_{i}^{n}, i=1, \ldots, M-1$, in (11). When the analytical solutions of ADE are used with data from the miscible displacement experiments, the common approach is to use the solution for the semi-infinite domain, and to fit the simulated time series of the solute concentrations at the column outlet distance to the experimental BTC [35]. We followed this approach using numerical solutions by setting the zero concentration at the right boundary and moving it far enough, so that the concentration at this boundary at the end of the transport simulations would not be greater than $10^{-6}$ of the maximum inlet concentration.

At the inlet, the nodal concentrations were set to provide mass conservation [29]. If $M_{\text {ins }}^{\mathrm{n}}$ corresponds to the solute mass inside the column at the time step $n$ and $M_{\text {ent }}$ stands for the solute mass that has entered the transport domain at one time step, the conservation of the mass requires that

$M_{\text {fnt }}=M_{\text {ins }}^{n+1}-M_{\text {ins }}^{n}$

This equation can be solved explicitly to obtain the boundary concentration $c_{0}^{n+1}$. The value of $M_{i n s}^{\dagger}$ was computed as

$M_{\text {ins }}^{\prime \prime}=\sum_{i=1}^{M-1} c_{i}^{\prime \prime h} h+c_{0}^{n}(h / 2)$

When the tracer is injected into the soil column during the pulse time duration, $t_{p}$, one has $M_{e n t}=v \Delta t$ for any timestep $n$ such that $n, \Delta t$ is smaller than $t_{p}$ and $M_{e n t}=0$ otherwise. For a continuous pulse, $t_{p}$ is infinite.

\section{Data source and fitting procedure}

We used published data on 53 breakthrough curves from seven experiment sets. Table 1 presents the information about experimental conditions. These experiments corresponded to miscible displacement in columns for a variety of soils (see Table 1) having different textures. The lengths and the diameters of the columns 
Table 1

Selected experimental conditions, optimum values of parameter $\alpha$ and corresponding root-mean-squared errors (RMSE)

\begin{tabular}{|c|c|c|c|c|c|c|c|}
\hline Soil & Disturbed fundisturbed & Tracer & Flow velocity $\left(\mathrm{cm} \mathrm{h}^{-1}\right)$ & Saturated & Water content & Optimum alpha & RMSE \\
\hline \multicolumn{8}{|c|}{ Biggar and Nielsen [37] } \\
\hline Columbia & Disturbed & Chloride & 0.2 & No & 0.482 & 1.9 & 0.01104 \\
\hline Columbia & Disturbed & Tritium & 0.2 & No & 0.482 & 2 & 0.01269 \\
\hline Columbia & Disturbed & Chloride & 0.2 & No & 0.472 & 1.15 & 0.01736 \\
\hline Columbia & Disturbed & Tritium & 0.2 & No & 0.472 & 1.55 & 0.01315 \\
\hline \multicolumn{8}{|l|}{ Cassel et ai. $|38|$} \\
\hline Beotia & Disturbed & Nitrate & 0.0151 & No & 0.391 & 1.2 & 0.01262 \\
\hline Beotia & Disturbed & Chloride & 0.0151 & No & 0.391 & 1.05 & 0.00261 \\
\hline Beotia & Undistubed & Nitrate & 0.0151 & No & 0.324 & 1.15 & 0.01085 \\
\hline Beotia & Undistubed & Chloride & 0.0151 & No & 0.324 & 1.45 & 0.00216 \\
\hline Aberdeen & Disturbed & Nitrate & 0.0151 & No & 0.378 & 1.85 & 0,01005 \\
\hline Aberdeen & Disturbed & Chloride & 0.0151 & No & 0.378 & 1.85 & 0,00515 \\
\hline Aberdeen & Undisturbed & Nitrate & 0.0151 & No & 0.346 & 2 & 0.01888 \\
\hline Aberdeen & Undistubed & Chloride & 0.0151 & No & 0.346 & 1.95 & 0.01046 \\
\hline \multicolumn{8}{|c|}{ McMahon and Thomas [40] } \\
\hline Maury & Undisturbed & Cliloride & 0.17 & Yes & 0.338 & 1.75 & 0.01884 \\
\hline Maury & Undisturbed & Tritium & 0.17 & Yes & 0.338 & 1.15 & 0.02031 \\
\hline Maury & Disturbed & Chloride & 0.17 & Yes & 0.339 & 2 & 0.02068 \\
\hline Maury & Disturbed & Tritium & 0.17 & Yes & 0.339 & 1.55 & 0.0139 \\
\hline Pembroke & Undisturbed & Tritium & 0.17 & Yes & 0.324 & 2 & 0.0122 \\
\hline Pembroke & Undisturbed & Chloride & 0.17 & Yes & 0.324 & 1.75 & 0.01507 \\
\hline Pembroke & Disturbed & Tritium & 0.17 & Yes & 0.335 & 1.65 & 0.01552 \\
\hline Pembroke & Disturbed & Chloride & 0.17 & Yes & 0.335 & 2 & 0.02207 \\
\hline Eden & Undisturbed & Chloride & 0.17 & Yes & 0.384 & 2 & 0.03931 \\
\hline Eden & Undisturbed & Tritium & 0.17 & Yes & 0.384 & 1.6 & 0.01173 \\
\hline Eden & Disturbed & Chloride & 0.17 & Yes & 0.396 & 1.3 & 0.01651 \\
\hline Eden & Disturbed & Tritium & 0.17 & Yes & 0.396 & 1.05 & 0.01653 \\
\hline \multicolumn{8}{|l|}{ Rao et al. $|39|$} \\
\hline Molokai & Disturbed & Tritium & 5.82 & Yes & 0.626 & 1.7 & 0.00941 \\
\hline Waliawa & Disturbed & Tritium & 6.84 & Yes & 0.644 & 2 & 0.00778 \\
\hline \multicolumn{8}{|c|}{ Nielsen and Biggar [36] } \\
\hline Yolo & Disturbed & Chloride & 0.04 & Yes & ND & 2 & 0.01436 \\
\hline Yolo & Disturbed & Chloride & 1.89 & Yes & $\mathrm{ND}$ & 1.2 & 0.0116 \\
\hline Columbia & Disturbed & Chloride & 0.05 & Yes & ND & 2 & 0.0125 \\
\hline Columbia & Disturbed & Chloride & 2.49 & Yes & ND & 2 & 0.00989 \\
\hline Dakley & Disturbed & Chloride & 0.28 & No & 0.27 & 1.15 & 0.02465 \\
\hline Oakley & Disturbed & Chloride & 0.27 & No & 0.33 & 1.15 & 0.03561 \\
\hline Oakley & Disturbed & Chloride & 0.3 & No & 0.36 & 1.15 & 0.01176 \\
\hline Glass beads & Disturbed & Chloride & 1.54 & No & 0.17 & 2 & 0.04636 \\
\hline Glass beads & Distubed & Chloride & 1.77 & No & 0.34 & 2 & 0.02578 \\
\hline \multicolumn{8}{|l|}{ Jardine et ol. [42] } \\
\hline $\mathrm{ND}$ & Undisturbed & Bromide & 8.05 & No & 0.549 & 2 & 0.02635 \\
\hline ND & Undisturbed & Bromide & 1.5 & No & 0.533 & 2 & 0.03431 \\
\hline ND & Undisturbed & Bromide & 0.18 & No & 0.513 & 1.15 & 0.01006 \\
\hline ND & Undisturbed & Bromide & 0.03 & No & 0.419 & 1.15 & 0.00548 \\
\hline \multicolumn{8}{|c|}{ Seyfried and Rao [41] } \\
\hline Typic Distropept & Undisturbed & Tritium & 26.4 & Yes & 0.57 & 2 & 0.03282 \\
\hline Typic Distropept & Undisturbed & Tritium & 2.7 & Yes & 0.57 & 2 & 0.01075 \\
\hline Typic Distropept & Undisturbed & Tritium & 19.5 & Yes & 0.57 & 2 & 0.02432 \\
\hline Typic Distropept & Undisturbed & Tritium & 5.9 & Yes & 0.55 & 2 & 0.01022 \\
\hline Typic Distropept & Undisturbed & Tritium & 1.2 & No & 0.53 & 2 & 0.01535 \\
\hline Typic Distropept & Undisturbed & Tritium & 0.2 & No & 0.52 & 1.75 & 0.01052 \\
\hline Typic Distropept & Undisturbed & Tritium & 28.7 & Yes & 0.6 & 2 & 0.0143 \\
\hline Typic Distropept & Undisturbed & Tritium & 1.3 & No & 0.59 & 1.5 & 0.00661 \\
\hline Typic Distropept & Undisturbed & Tritium & 19.7 & Yes & 0.55 & 2 & 0.06093 \\
\hline Typic Distropept & Undisturbed & Tritium & 1.7 & No & 0.52 & 2 & 0.01258 \\
\hline Typic Distropept & Undisturbed & Tritium & 29.4 & Yes & 0.54 & 2 & 0.07177 \\
\hline Typic Distropept & Undisturbed & Tritium & 0.9 & No & 0.52 & 2 & 0.01747 \\
\hline Typic Distropept & Undisturbed & Tritium & 24.7 & Yes & 0.53 & 2 & 0.01636 \\
\hline Typic Distropept & Undisturbed & Tritium & 2.1 & No & 0.51 & 1.8 & 0.00649 \\
\hline
\end{tabular}

varied between 10 and $84 \mathrm{~cm}$ and between 3.5 and $30 \mathrm{~cm}$, respectively. Soil structure was natural in some columns, and was artificial, or disturbed, in others. Both water-saturated and unsaturated soils were used in the experiments. Chloride, tritium and bromide were the tracer jons. The flow velocities ranged between 0.015 and $29.4 \mathrm{~cm} \mathrm{~h}^{-1}$ (Table 1 ). The BTC data points were obtained by digitizing graphs found in the selected publications. The digitizing was made in triplicate. Coefficients of variation within the replications did not exceed $0.1 \%$.
The range of $\alpha^{\prime}$ s ( $1<\alpha \leqslant 2$ ) was scanned in increments of 0.05 For each value of $\alpha, D_{f}$ and $v$ were estimated using a version of the Marquardt-Levenberg algorithm [43] to minimize the rootmean-squared error (RMSE):

RMSE $=\sqrt{\sum_{j=1}^{N}\left(c_{j}^{\text {colc }}-c_{j}^{\text {nteas }}\right)^{2} / N}$ 

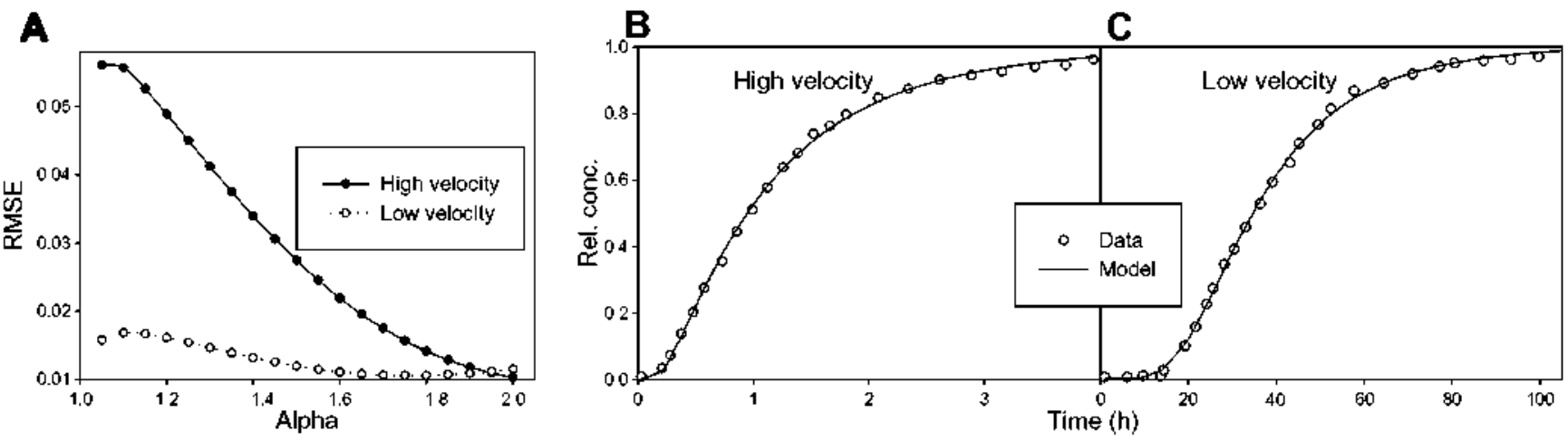

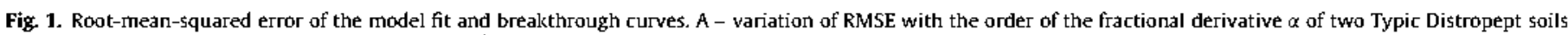

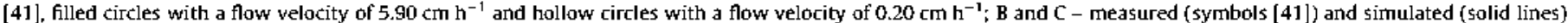
breakthrough curves of the high and low flow rates, respectively. The best fit was obtained for $\alpha=2.0$ in the case of high flow rates and $\alpha=1.75$ for the low flow case.

\section{Results and discussion}

Fig. 1 shows the typical result of the parameter estimation procedure. The dependence of the RMSE (12) values on the order of the fractional derivative $\alpha$ is shown in Fig. 1A for Typic Distropept soils with two different flow rates of 5.90 and $0.20 \mathrm{~cm} \mathrm{~h}^{-1}$, and similar saturation degree of 0.550 and 520 water content, respectively [41]. The simulated BTC are compared with measured BTC in the plots 1B (high flow) and $1 \mathrm{C}$ (slow flow) for the values of $\alpha$, $D_{f}$ and $v$ corresponding to the minimum RMSE. In both cases the minimum RSME were 0.010. In the case of high flow rates (Fig. 1B) this minimum value was attained with $\alpha=2.0$ and with $x=1.75$ (Fig. 1C) in the case of low flow.

Overall, the FADE, as a general model that includes the ADE, accurately simulates experimental breakthrough curves from miscible experiments in soil columns. In this study, 31 out of 53 breakthrough curves are fitted with the RMSE less than 0.019 and the largest RSME is 0.072 (see Table 1).

From the 53 experimental BTCs considered, 28 are better fitted with $\alpha$ smaller than 2.00 , i.e. with the FADE, and 25 are best fitted with $\alpha=2.00$, i.e. with the classical ADE. This suggests the necessity to use the FADE rather than the $A D E$ as a general framework to simulate solute transport in soil. The differences in values of the optimal parameter $\alpha$ presumably reflect different degrees of complexity of the solute particles movement in soil. The latter, in turn, might reflect the differences in the hierarchical structure of soil pore space for each particular case. Relating $\alpha$ to pore space geometry presents an interesting research avenue to explore. Data on soil pore space tomography coupled with the column transport data can be very useful in this respect.

Optimal values of $\alpha$ tended to vary with type of soil, type of tracer, flow velocity and saturation degree. For the Oakley soil from Ref. [36], $\alpha$ was 1.15 while it was 2.00 for the others soils of this dataset, except in the case of the Yolo soil with highest flow velocity $\left(1.89 \mathrm{~cm} \mathrm{~h}^{-1}\right)$. ln the dataset from Ref. [38] the optimal values of $\alpha$ for Beotia BTCs were lower than for Aberdeen soils; these values were between 1.05 and 1.45 for Beotia soils while $\alpha$ was between 1.85 and 2.00 for Aberdeen soils. There was also a substantial difference between Molokai and Wahiawa soils from Ref. [39]. In the case of the dataset from Ref. [40] the highest values of $\alpha$ corresponded to disturbed Maury and Pembroke soils under saturated conditions and chloride as a tracer.

Values of $\alpha$ were larger for tritium than for chloride. This was the case for the experiments in [37] under the same saturated conditions and also for the Maury (with high water content), Eden (with high water content) and Pembroke soils of the experiments in [40]. One reason for that may be the difference between pore spaces available to these two tracers. Chloride transport is affected by the anion exclusion that greatly decreases its concentrations in the vicinity of charged surfaces of soil particles.

The degree of soil saturation with water affected the optimum value of parameter $\alpha$. In general, unsaturated soils had values of $\alpha$ smaller than two. This trend is particularly clear in the experiments from [38]. For the same soil, a decrease in the saturation degree produced a decrease in the optimum value of parameter $\alpha$, e.g. data from $[37,42]$. The decrease in the saturation degree may create more complex pathways of the solute movement after emptying the large pores that dominate transport in saturated soil.

There was some interplay between effects of flow velocity and soil water saturation. The increase in the optimum value of $\alpha$ with the increase in flow velocity was observed with data from $[36,39,42]$. Lower values of $\alpha$ were related to lower flow velocities in the dataset from [41]. At the same saturation degree, one may expect the increase in pore water velocity to result in a more distinct separation of the pore space into slow- and high-speed transport zones, and therefore a larger probability for values of $\alpha$ to have values less than 2 .

\section{Conclusions}

The FADE constitutes a broad framework that includes the ADE and considers solute particles undergoing motions that are more complex than Brownian motion. Differences in values of the parameter $\alpha$ presumably reflect differences in hierarchical geometries of soil pore spaces. The FADE has accurately simulated the breakthrough curves considered in this study. The values of $\alpha$ ranged from 1.05 to 2.00 . From the 53 experimental breakthrough considered, 28 were better fitted with $\alpha$ smaller than two, and 25 are best fitted with ADE, i.e. $\alpha=2$. Trends of the increase in values of $\alpha$ with the increase in saturation and in flow velocity have been observed for this particular dataset. The fractional advective-dispersive equation as a generalization of classical advective-dispersive equation is a promising enhancement in the hydrologist toolbox.

\section{Acknowledgements}

Fernando San Josê Martinez was supported in part by a grant of Secretaría de Estado de Universidades e Investigacion (Ministerio de Educacion y Ciencia, Spain), the Plan Nacional de Investigación Científica, Desarrollo e Innovación Tecnológica (1+D+[) under Ref. AGL2007-62648 Spain and DGUl (Comunidad de Madrid) and UPM (Universidad Politécnica de Madrid) under Ref. $M$ 0700204135 . 


\section{References}

[1] Jury WA, Flühler $H$. Transport of chemical through soil: mechanics, models and flied experiments. Adv Agron 1992;47:141-201.

[2] Bhatacharya R, Gupta VK. Application of the central limit theorem to solute transport in saturated porous media: from kinetic to field scales. In: Cushman $\mathrm{JH}$, editor. Dynamics of fluids in hierarchical porous media. New York: Academic Press; 1990. p. 97-124.

[3] Jury WA. Solute transport and dispersion. In: Steffen Wl. Denmead OT, editors. Flow and transport in the natural environment: advances and applications. Berlin: Springer-Verlag; 1988. p. 1-16.

14] Khan AUH. Jury WA A laboratory test of the dispersion scale effect. J Contam Hydrol 1990;5:119-32.

[5] Porro I, Wierenga PJ. Hills RG. Solute transport through large uniform and Iayered soil columns. Water Resour Res 1993;29:1321-30.

[6] Snow VO, Clothier BE, Scotter DR, White RE. Solute transport in a layered field soil: experiments and modelling using the convection-dispersion approach. J Contam Hydrol 1994; 16:339-58.

[7] Yasuda $H$, Berndtsson $R_{+}$Barri $A_{4}$ Jinno $K$. Plot-scale solute transport in a semiarid agricultural soil. Soil 5ci Soc Am J 1994:58:1052-60.

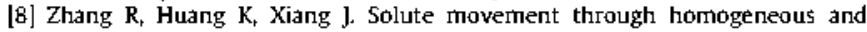
heterogeneous soil columns. Adv Water Resour 1994:17:317-24.

[9] Pachepsky YA, Benson DA, Rawls WJ. Simulating scale-dependent solute transport in soils with the fractional advective-dispersive equation. Soil Sci Soc AII J 2000;64:1234-43.

[10] van Genuchten MTh, Wierenga PJ. Mass transfer in sorbing porous media: l. Analytical solutions. Soil 5ci Soc Am I 1976;40:473-81.

[11] Nielsen DR, van Genuchten MTh, Biggar JW. Water flow and solute transport processes in the unsaturated zone. Water Resour Res 1986;22(Suppl. 9): $895-1085$

[12] Vachaud $G$, Vauclin $M$, Addiscott TM. Solute transport in the vadose zone: a review of models. In: Proceedings of the international symposium on water quality modelling of agricultural non-point sources, Part 1, 19-23 June 1988, Logan, UT. USDA-ARS, US Gov. Print. Office, Washington, DC, 81-104; 1990.

|13| Bouchard JP. More Lévy distributions in physics. In: Shlesinger MF, Zaslavsky $G M$, Frisch $U$, editors. Lévy flights and related topics in physics. New York: Springer; 1995. p. 239-50.

[14] Weeks ER, Solomon TH. Urbach JS, Swinney HL. Observation of anomalous diffusion and Lévy flights. In: Shlesinger MF, Zaslavsky GM, Frisch U, editors. lévy flights and related topics in pluysics. New York: Springer-Verlag; 1995. p. 51-71.

|15| Benson DA. Wheatcraft SW. Meerschaert MM. Application of a fractional advection-dispersion equation. Water Resour Res 2000;36(6):1403-12.

[16] Zaslavsky GM. Renormalization group theory of anomalous transport in systems with Hamiltonian chaos. Chaos $1994 ; 4(1): 25-33$.

[17] Compte A. Stochastic foundations of fractional dynamics. Phys Rev E 1996;53(4):4191-3.

|18| Compte A. Continuous time landom walks on moving fluids. Plyys Rev E 1997;55(6):6821-31.

|19| Saichev Al. Zaslavsky GM. Fractional kinetic equations: solutions and applications. Chaos 1997;7:753-64.

[20] Benson DA. The fractional advection-dispersion equation: development and application. PhD thesis, University of Nevada, Reno; 1998.

[21] Chaves AS. A fractional diffusion equation to describe lévy flights. Phys Lett A 1998;239:13-6.

[22] Metzler R, Klafter J, Sokolov IM. Anomalous transport in external fields: continuous time ransom walks and fractional diffusion equations extended. Pliys Rev E 1998:58:1621-33.
[23] Samko SG. Kilbas AA, Marichev Ol. Fractional integl'als and derivatives: theory and applications. New York: Gordon and Breach Science Publ.; 1993.

[24] Benson DA, Schumer R. Meerschaert MM. Wheatcraft 5W. Fractional dispersion, Levy motion, and the MADE tracer tests. Transp Porous Media 2001;42:211-40.

[25] Lu 5, Molz F]. Fix G]. Possible problems of scale dependency in applications of the three-dimensional fractional advection-dispersion equation to natural porous media. Water Resour Res 2002;38(9):1165. doi:10.1029 2001 WR000624.

[26] Zhou L7. Selim HM. Application of the fractional advection-dispersion equation in porous media. Soil Sci Soc Am J 2003;67(4):1079-84.

[27] Deng ZO, Singh VP, Bengtsson L. Numerical solution of fractional advectiondispersion equation. ASCE J Hydraul Eng 2004;130(5):422-31.

[28] Zhang X, Crawford JW, Deeks $\mathbf{L K}$, Stutter Ml, Bengough AG, Young IM. A mass balance based numerical method for the fractional advection-dispersion equation: theory and application. Water Resour Res 2005:41:W07029. doi: 10,102952004 WRO03818.

[29] San Jose Martinez F. Pachepsky YA. Rawls W. Solute transport simulated with the fractional advective-dispersive equation. In: Agrawal O, Tenreiro Machado $J A$, Sabatier $J$, editors. Fractional derivatives and their applications, IDECT ClE2005: 2005. ISBN: 0-7918-3766-1.

[30] Lynch VE, Carreras BA, del-Castillo-Negrete D, Ferreiras-Mejias KM, Hicks HR Numerical method for the solution of partial differential equations with fractional order. J Comput Phys 2003;192:406-21.

[31] Oldham KB, Spanier J. The fractional calculus. New York: Academic Press: 1974.

[32] Liu F, Anh V, Turner I. Numerical solution of the space fractional Fokker-Planck equation. J Comput Appl Math 2004;166:209-19.

[33] Meerschaert MM, Tadjeran C. Finite difference approximation fo fractional advection-dispersion flow equations. J Comput Appl Math 2004: 172:65-77.

[34] Meerschaert MM, Tadjeran C. Finite difference approximations for two-sided space-fiactional partial differential equations. Appl Numer Math 2006: 56:80-90.

[35] Toride N, Leij FJ, van Genuchten MTh. The CXTFI code for estimating transport parameters from labolatory or field tracer experiments. Version 2.0. Research rep 137, US Salinity Lab, Riverside (CA); 1995.

[36] Nielsen DR, Biggar JW. Miscible displacement in soils: I. Experimental information. Soil 5ci 5oc Proc 1961;25:1-4.

[37] Biggar JW, Nielsen DR. Miscible displacement in soils: ll. Behaviour of tracers. Soil Sci Soc Proc 1962;26:125-8.

[38] Cassel DK, Krueger TH, Schroer FW, Norum EB. Solute movement through disturbed and undisturbed soil cores. Soil Sci Soc Am Proc 1974;38:36-40.

[39] Rao PSC, Green RE. Aluja LR, Davidson JM. Evaluation of a capillary bundle model for describing solute dispersion in aggregated soils. Soil Sci Soc Am J 1976;40:815-20.

[40] McMahon MA. Thomas GW. Chloride and titrated water flow in disturbed and undisturbed soil cores. Soil Sci Soc Am Proc 1974;28:727-32

[41] Seyfried MS. Rao PSC. Solute transport in undisturbed columns of an aggregated tropical soil: preferential flow effect. Soil Sci Soc Am J 1987;51: 1434-44.

[42] Jardine PM. Jacobs GK. Wilson GV. Unsaturated transport processes in undistubed heterogeneous porous media: I. lnorganic contaminants. Soil SC Soc Am J 1993:57:945-53.

[43] van Genuchten MTh. Non-equilibrium transport parameters from miscible displacement experiments. Research Rep. No. 119. US Salinity laboratory USDA-SEA-ARS, Riverside (CA); 1981. 